\title{
Looking Toward the Next Fifty Years at the Journal of the History of Biology
}

\author{
MICHAEL R. DIETRICH \\ History and Philosophy of Science Department \\ University of Pittsburgh \\ Pittsburgh \\ USA \\ E-mail:mdietrich@pitt.edu
}

This issue closes out the first 50 volumes of the Journal of the History of Biology, as well as my six-year term as Editor-in-Chief. In this memorial year, we have featured reflections from $J H B$ 's past Editors. In this final issue of volume 50, I am pleased to include the reminiscences of our founding Editor, Everett Mendelsohn. It is no exaggeration to say that without Everett there would have been no $J H B$, and that history of biology as a field would not have become what it is today. As Everett notes, it is remarkable to see how $J H B$ and the history of biology have flourished.

As we look to the next 50 years of $J H B$, we have every reason to continue to be optimistic. History of biology is a growing and vibrant field of history. Just as it has for 50 years, $J H B$ will continue keep pace with developments in history and biology. As always, $J H B$ will remain a great venue for a beginning scholar's first history of biology article, for a senior scholar's experienced assessment of the field, and for everything in between.

Looking forward, I am very pleased to be able to hand over $J H B$ to an excellent, new editorial team. Karen Rader of Virginia Commonwealth University and Marsha Richmond of Wayne State University will share duties as Co-Editors-in-Chief beginning with Volume 51 in 2018. Karen and Marsha bring with them tremendous scholarly expertise in the history of biology. They have also both served as members of the $J H B$ Editorial Board and as Associate Editors. Over the past few months, they have been learning the day to day workings of the Editorial Manager manuscript system, and are prepared to seamlessly 
take over the running of the journal and to implement new ideas that will certainly make it better.

Marsha and Karen will be joined by a new book review editor, Lijing Jiang, from the Chemical Heritage Foundation. Lijing takes over from Mark Borrello from the University of Minnesota, who for the past 6 years has managed the book review process at $J H B$.

As Mark and I move on to other challenges, we are indebted to the support we have received from Springer, from the Editorial Board, and from hundreds of reviewers that have generously contributed their insights as part of the editorial process. We wish Karen, Marsha, and Lijing every success. We leave confident in the future of $J H B$, and grateful for the opportunity to help a great group of scholars find their way into print. 